\title{
Crustal anisotropy and deformation of the southeastern margin of the Tibetan \\ Plateau revealed by Pms splitting
}

\author{
Yan Cai ${ }^{1}$, Jianping $\mathrm{Wu}^{1,2}$, Lihua Fang ${ }^{1,2}$, Weilai Wang ${ }^{1}$, Shuang $\mathrm{Yi}^{3}$ \\ ${ }^{1}$ Institute of Geophysics, China Earthquake Administration, Beijing 100081, China. \\ ${ }^{2}$ Key Laboratory of Seismic Observation and Geophysical Imaging, Institute of \\ Geophysics, China Earthquake Administration, Beijing 100081, China. \\ ${ }^{3}$ Key Laboratory of Computational Geodynamics, University of Chinese Academy of \\ Sciences, Beijing 100049, China. \\ Correspondence to: Jianping Wu, wjpwu@cea-igp.ac.cn
}

\begin{abstract}
The crustal seismic anisotropy in the southeastern margin of the Tibetan Plateau was obtained by analyzing receiver functions of a newly deployed dense seismic array. The measured splitting time of the Pms phase varies from 0.02 to $0.88 \mathrm{~s}$, with an average value of approximately $0.28 \mathrm{~s}$, which is much larger than the splitting time in the upper crust (top $15 \mathrm{~km}$ ), implying that the crustal anisotropy is mainly generated within the middle and lower crust (below $15 \mathrm{~km}$ ). The fast polarization directions of Pms are in good agreement with the directions of principle compression stress in the sub-blocks and are parallel with the strikes of the faults near the Xiaojiang fault, the Red River fault, and the Lancangjiang fault. The splitting time shows a conspicuous contrast with a small value in the east of the Xiaojiang fault zone and a large value in
\end{abstract}


the west. We assume that the differential movement in the ductile middle-to-lower crust caused the alignment of materials along the movement directions and developed the crustal anisotropy in the sub-blocks. Near the major faults, the low-velocity zone, high Poisson's ratio and high heat flow in the crust provide evidence for the existence of partial melt, which may be related to the strong crustal anisotropy in this area. The crustal deformation near these faults is mainly caused by the strike-slip motion, resulting in the alignment of minerals and partial melts along the strikes of these faults. Analyzing the anisotropy pattern from SKS and Pms splitting, we speculate that the crustal deformation is mechanically decoupled from the upper mantle in our study region.

Keywords: Tibetan Plateau, anisotropy, receiver function, crustal deformation, Pms splitting 


\section{Introduction}

Before $50 \mathrm{Ma}$, Indian plate collided with Eurasian plate, inducing intense deformation and crustal shortening in the Tibetan Plateau (Molnar and Tapponnier, 1975; Rowley, 1996). As the tectonic transitional zone between the uplifting Tibetan Plateau and the Yangtze block (Fig. 1), the SE margin of the Tibetan Plateau is of particular interest. Though studied for decades, the mechanisms of crustal deformation and southeastward expansion of the Tibetan Plateau remain controversial. GPS velocity field indicates that there is a clockwise rotation around the eastern Himalaya syntaxis in our study region (Replumaz and Tapponnier, 2003; Shen et al., 2001; Liang et al., 2013). SKS splitting results show that the fast polarization directions change around $26^{\circ} \mathrm{N}$, being NS to the north and EW to the south (Flesch et al., 2005; Lev et al., 2006; Wang et al., 2008). These observations mostly reflect the surface and upper mantle deformation, and thus, more information about the deep crustal deformation in this region is needed to deepen our understanding of the large-scale deformation.

Seismic anisotropy has been considered quite an effective method to study the deformation of deep structures (Crampin and Lovell, 1991; McNamara and Owens, 1993; Silver, 1996). In recent years, several researchers have discussed the crustal anisotropy beneath the SE margin of the Tibetan Plateau using the Pms phase of the receiver function from sparse seismic networks (Chen et al., 2013; Sun et al., 2012; Yang et al., 2015). In Sun et al.'s work (2012), they suggested that the crustal anisotropy beneath the SE Tibetan Plateau plays important roles in the crust-to-upper 
mantle anisotropy detected by SKS splitting and speculated that the deformation in the upper mantle is weak or vertical. Chen et al. (2013) considered major active faults and deep crustal interiors to be the main causes of the deep deformation and the deformation of crust in the northernmost Indochina block, which is decoupled from the upper mantle. Yang et al. (2015) concluded that the crustal anisotropy on the SE Tibetan plateau is mainly affected by the eastward extrusion of the Tibetan plateau. These results are important to deformation studies of the SE Tibetan plateau, but the spatial resolution is not high enough due to the lack of dense seismic stations.

In this work, we use the data recorded by a newly deployed dense seismic array on the SE margin of the Tibetan Plateau to calculate the receive functions and extract the crustal anisotropy parameters. Our new results provide a detailed geographical variation of the local anisotropic parameters and new insights on the deep structural deformation of the SE margin of the Tibetan Plateau.

\section{Data and Methods}

We use a new set of teleseismic records obtained by 285 broadband digital seismic stations of the China Array (ChinArray, 2006; ChinArray-Himalaya, 2011) on the SE margin of the Tibetan Plateau. Among them, 50 stations operated from December 2008 to December 2010 and 235 stations operated from June 2011 to November 2013. The seismic stations were equipped with seismometers of CMG-40T or CMG-3ESPC. The average inter-station distance is approximately $35 \mathrm{~km}$, which is much denser than 
that of the permanent stations in this region. In total, 1260 teleseismic events (Fig. 2) with an epicentral distance between $30^{\circ}$ and $90^{\circ}$, a magnitude larger than 5.5 and a SNR larger than 4.0 were selected to calculate the receiver functions. We extracted the receiver functions from teleseismic $\mathrm{P}$ waves using the maximum entropy deconvolution method (Burg, 1972; Clearbout, 1976; Wu et al., 2003).

With different epicentral distances, there is a slight moveout in the arrival time of the Pms phase relative to the direct $\mathrm{P}$ wave. Using a layered velocity structure referenced to the seismic sounding profile (Zhang et al., 2006; Zhang et al., 2005a; Zhang et al., 2005b) with a modified Moho depth from H-א stacking technology (Zhu and Kanamori, 2000), we calculated the arrival time of the Pms in different layers and made corrections so that the arrival time of the Pms is equivalent to that from a source with an epicentral distance of $60^{\circ}$. The corrected receiver functions are binned and stacked in $5^{\circ}$ bins with backazimuth. The minimum number of receiver functions after stacking is 21 , and the average number is 38 . We selected the stations where the receiver functions should be in each backazimuthal quadrant.

The azimuthal variation of the radial receiver function is analyzed to study the crustal anisotropy, which will bring a $\cos 2 \theta$ variation to the arrival time of the Pms. In this research, we select the stations with this characteristic (Sun et al., 2012) and use a comprehensive technique to robustly estimate crustal anisotropy using the Pms phase by calculating four objective functions (Liu and Niu, 2012). The three individual 
objective functions are shown below.

(1) Maximization of the peak energy of the stacked Pms phase in the radial receiver functions. Since the arrival time of the Pms shows a $\cos 2 \theta$ variation with the backazimuth, which can be evaluated by a cosine function, the fast polarization direction and splitting time can be estimated from the amplitude and phase of the cosine function. (2) Maximization of the cross-correlation of the Pms phase in the radial receiver functions. As we all know, in the isotropic medium, the radial receiver functions at a station have a high cross-correlation coefficient. For this reason, we could obtain the fast polarization direction and splitting time by maximizing the radial cross-correlation coefficient after removing crustal anisotropy. (3) Minimization of the total Pms energy of the stacked transverse receiver functions after a full correction of crustal anisotropy.

Next, the joint objective function was computed by taking the weighted average of the above three objective functions to fully utilize the anisotropic characteristics on the receiver functions. Consequently, the maximum value of the joint objective function could robustly extract anisotropic parameters. In the synthetic test, the parameters estimated from the joint method are very close to the model parameters (Liu and Niu, 2012). As long as the azimuthal coverage is sufficient, this method can obtain quite reliable crustal anisotropy results. 
In theory, after a correction with estimated anisotropy, the stacked Pms energy in the transverse receiver functions should be significantly weaker than the original value. Furthermore, the peak energy of the stacked Pms phase in the radial receiver functions should be much larger than that of the original receiver functions. For this reason, we applied a statistical analysis to test the robustness of the result. This method calculates the stacked energy of the Pms phase in the radial and transverse component before and after removing crustal anisotropy using equations (1) and (2).

$$
\begin{aligned}
& E_{r}^{i}=\left[\sum_{j=1}^{N} F_{r, j}^{i}(t)\right]_{\max }^{2} \cdot \\
& E_{t}^{i}=\int_{t 1}^{t 2}\left\{\sum_{j=1}^{N}\left[F_{t, j}^{i}(t)\right]^{2}\right\} d t
\end{aligned}
$$

where $F_{r, j}^{i}$ and $F_{t, j}^{i}$ are the $j$ th radial and transverse receiver functions at the $i$ th station before or after the anisotropic correction, respectively. $E_{r}^{i}$ and $E_{t}^{i}$ represent the stacked energy of the Pms in the radial and transverse receiver functions before or after correcting the crustal anisotropy, respectively. $t \in[t 1, t 2], t 1=T O-T L / 2$, and $t 2=T O+T L / 2 . T L$ and $T O$ are the length and average value of the arrival time window of the Pms phase, respectively.

The ratio of the Pms energy after and before anisotropic correction is as follows,

$$
\sigma^{i}=E_{\text {after }}^{i} / E_{\text {before }}^{i}
$$

which could be an essential indicator for measuring the reliability of the anisotropy.

\section{Example at station 53133}

In Fig. 3, we show the four objective functions of station $53133\left(22.31^{\circ} \mathrm{N}, 100.51^{\circ} \mathrm{E}\right)$. 
The anisotropic parameters estimated from those objective functions clearly display crustal anisotropy beneath this station and are in good agreement with each other. We applied the statistical analysis (equation (1) - (3)) to station 53133. After correcting for the crustal anisotropy, the stacked energy of the Pms phase on the radial receiver functions and transverse component is 1.7 times larger and 0.6 times smaller than those before.

Fig. 4 shows the original and corrected receiver functions. The arrival time of the Pms in the original radial receiver functions presents a $\cos 2 \theta$ variation (Fig. 4a), and the polarity of the Pms phase in the transverse component changes with the backazimuth (Fig. 4b). After anisotropic correction, the radial component shows a good alignment in the travel time of the Pms phase, and the Pms is almost inconspicuous in the transverse component (Fig. $4 \mathrm{c}$ and $4 \mathrm{~d}$ ). We applied the test method to all the stations, and the results (Table 1) indicate that the anisotropy estimations in this study are reliable.

\section{Result and Discussion}

We calculated the radial and transverse receiver functions at 285 stations, and then selected those stations with clear Pms phases, sufficient azimuthal coverage and clear $\cos 2 \theta$ variation in the arrival time of the Pms to measure the Pms splitting parameters. We obtained robust anisotropy estimations at 217 stations (Fig. 5). The splitting time of the Pms phase varies from 0.02 to $0.88 \mathrm{~s}$, with an average of approximately $0.28 \mathrm{~s}$ 
in the study region. It is difficult to define the depth distribution of the crustal anisotropy if only the Pms phase is analyzed. However, the anisotropy in the upper crust could be constrained by the shear wave splitting of local earthquakes (Crampin and Chastin, 2003; Shi et al., 2012). Shi et al. (2012) estimated the crustal anisotropy in Yunnan area from shear wave splitting using the local earthquakes recorded by a regional seismic network. Their results showed that the average time delay of the shear wave splitting was $1.8 \pm 1.2 \mathrm{~ms} / \mathrm{km}$. We conducted a statistical analysis of the focal depths and found that $93 \%$ of the earthquakes in Yunnan area are located above a depth of $15 \mathrm{~km}$ (the earthquake catalogue is from the China Earthquake Networks Center). The measured time delay between the fast and slow components represents the integrated anisotropy along the ray paths, which are between the crustal earthquakes and the overlying seismic stations. In Yunnan region, the ray paths are mainly within the top $15 \mathrm{~km}$ of the crust. Therefore, the average cumulative splitting time within the top $15 \mathrm{~km}$ of the crust will be less than $0.04 \mathrm{~s}$ in this region. Compared with the average $0.28 \mathrm{~s}$ splitting time estimated from the Pms phase, the shear wave splitting delay time of the whole crust is approximately 6 times larger than that in the upper crust (top $15 \mathrm{~km}$ ). Thus, we suppose that the crustal anisotropy in the study area is mostly generated within the middle and lower crust (below $15 \mathrm{~km}$ ).

Generally speaking, the shallow crust often develops many microcracks due to the nonhydrostatic stress field. The anisotropy in the shallow crust is mainly caused by the aligned microcracks (Crampin and Peacock, 2008; Rabbel and Mooney, 1996). 
Subjected to the compression force, the microcracks perpendicular to the force close, and those parallel to the force open. Thus, the fast polarization directions of the anisotropy caused by the microcracks are parallel to the compression force. So what is the main cause of the deep crustal anisotropy? It is generally considered that the alignment of the minerals in rocks is the main cause of the anisotropy in the middle and lower crust (Barruol and Mainprice, 1993; Tatham et al., 2008; Weiss et al., 1999). Rocks rich in micas and amphiboles always exhibit strong crustal anisotropy. Under a compression force, the minerals may be aligned with the maximum shear stress or tension stress, which is not parallel to the compression force.

For studying the relationships between crustal anisotropy and surface deformation, we calculated the strain rate from the GPS observations (Liang et al., 2013). Kriging interpolation was adopted to interpolate the GPS data to grid values, and the calculation details are described in Zhu et al. (2005). As shown in Fig. 5, the fast polarization directions in western Yunnan sub-block (WYB) clearly present a clockwise rotation. In southern Yunnan sub-block (SYB), the directions are nearly NW-SE in the east, NE-SW in the west and N-S in the central block, and in south China block (SCB), they are mostly NW-SE. Compared with the strain rate field, we found that the fast polarization directions in different sub-blocks are nearly parallel with the directions of the principle compression stress. Thus, we could not use the above model to explain the consistent nature of the fast polarization directions and compression force. As mentioned previously, the crustal anisotropy is mostly from the 
middle and lower crust. We consider that under the eastward extrusion of Tibetan Plateau, the brittle shallow crust may move faster than the ductile middle-to-lower crust. The differential movement in the ductile crust may cause the alignment of the materials along the movement directions, developing the crustal anisotropy. In addition, the splitting time shows a conspicuous contrast, with a small value in the east of XJF zone and a large value in the west. Thus, the differences of the splitting time in the two sides of XJF imply that XJF zone has a clear impact on the eastward extrusion of the materials from the Tibetan Plateau, and the extrusion is distinctly weakening in the east of XJF.

Near XJF, the middle and south branch of RRF, and the middle branch of LCJF, the fast polarization directions are mostly aligned with the strikes of the faults. We speculate that the crustal anisotropy near these faults has different models from those in the sub-blocks. Previous studies found that XJF, RRF and LCJF penetrate into the upper mantle (Kan et al., 1986; Wang et al., 2014). Furthermore, tomography, receiver functions, and geothermal research found that low $\mathrm{P}$ wave and $\mathrm{S}$ wave velocity structures with high average crustal Poisson's ratio (Bao et al., 2015; Fan et al., 2015; Hu et al., 2005; Wang et al., 2003; Wang et al., 2014; Wu et al., 2001; Wu et al., 2013) and high heat flow (Hu et al., 2000) exist in the crust beneath these faults. These features indicate the existence of partial melt in the crust. Although the alignment of the minerals in rocks is considered to be the main cause for anisotropy in the deep crust (Barruol and Mainprice, 1993; Tatham et al., 2008; Weiss et al., 1999), some 
experiments proved that the aligned melts can also generate strong anisotropy, which is close to or even greater than the anisotropy from the alignment of the minerals in rocks (Katz et al., 2006; Kohlstedt and Zimmerman, 2003). Therefore, we think that the strike-slip motion of these faults caused the crustal deformation, resulting in the alignment of the minerals and partial melts along the strikes of these faults.

North of $\sim 26^{\circ} \mathrm{N}$, previous studies have agreed that the deformation in the crust and upper mantle is coupled (Chang et al., 2015; Felsch et al. 2005; Meltzer et al. 2007; Wang et al., 2008), but south of $\sim 26^{\circ} \mathrm{N}$, there exists two deformation patterns. Felsch et al. (2005) compared the mantle deformation pattern from SKS splitting with the surface deformation. Meltzer et al. (2007) investigated the upper mantle anisotropy, GPS observations and plate movement. They both suggested that the crust and mantle completely decoupled in Yunnan area and the deformation in the mantle is dominated by simple asthenospheric flow. Wang et al. (2008) discussed the deformation pattern of the lithosphere on the eastern Tibetan Plateau from SKS splitting and GPS observations. They argued that the lithosphere is probably dominated by pure shear deformation, and the crust and mantle coupled mechanically during deformation, just like the vertically coherent deformation. If we assume that the deformation in the lithosphere is vertically coherent, the fast polarization directions from the Pms may present parallel with the directions from SKS splitting. Our results show clear differences with SKS splitting, and thus, we are inclined to conclude that the deformation in the crust and mantle is mechanically decoupled and the mantle 
deformation is mainly caused by the asthenospheric flow. The splitting time of the SKS phase ranges from $0.5 \sim 1.71 \mathrm{~s}$ (Fig. 5), with an average value of $0.96 \mathrm{~s}$ (Wang et al., 2008), which is more than three times that of the Pms splitting time, revealing that deformation in the upper mantle is much more intense than the deformation in the crust.

\section{Conclusion}

Pms phase splitting has been observed at most stations of a dense seismic array located on the SE margin of the Tibetan Plateau. Combining the anisotropic estimations at 217 stations with the surface deformation from GPS observations, velocity structures, local S wave splitting and SKS splitting in the study area, we draw the major conclusions as follows:

1. The measured splitting time of the Pms phase varies from 0.02 to $0.88 \mathrm{~s}$, with an average value of approximately $0.28 \mathrm{~s}$, which is much larger than the splitting time in the upper crust estimated from local $\mathrm{S}$ wave splitting. We inferred that the crustal anisotropy is mostly from the middle and lower crust in the study area.

2. Analyzing the relationships between our anisotropy results and surface deformation from GPS observations in the sub-blocks, we assume that differential movement in the ductile crust may cause the alignment of the materials along the movement directions, which causes the crustal anisotropy. 
3. The fast polarization directions near XJF, RRF, and LCJF are mostly consistent with the strikes of the faults, which were found penetrating into Moho depth. Other geophysical studies indicate the existence of partial melt beneath these faults. The crustal deformation caused by the strike-slip motion of these faults results in the alignment of the minerals and partial melts along the strikes of these faults.

4. The splitting time of the SKS phase is three times larger than that of the Pms phase, implying that the deformation in the upper mantle is much more intense than the deformation in the crust. Considering the different deformation patterns of Pms splitting and SKS splitting, we speculate that the crust is mechanically decoupled from the upper mantle in this region.

\section{Acknowledgments}

The waveform data were provided by China Seismic Array Data Management Center at Institute of Geophysics, China Earthquake Administration. This work was supported by National Science Foundation Grant of China (Grant No.41374097 and No. 41304043), China National Special Fund for Earthquake Scientific Research in Public Interest (Grant No. 201008001) and the Institute of Geophysics, China Earthquake of Administration (Grant No. DQJB13B08).

\section{Appendix A. Supplementary material}

Supplementary data associated with this article can be found in the attachment. 


\section{Reference}

Bao, X., Song, X., Li, J., 2015. High-resolution lithospheric structure beneath Mainland China from ambient noise and earthquake surface-wave tomography. Earth and Planetary Science Letters 417, 132-141.

Barruol, G., Mainprice, D., 1993. A quantitative evaluation of the contribution of crustal rocks to the shear-wave splitting of teleseismic SKS waves. Physics of the Earth and Planetary Interiors 78(3), 281-300.

Burg, J. P., 1972. The relationship between maximum entropy spectra and maximum likelihood spectra. Geophysics 37(2), 375-376.

Chang, L. J., Wang, C. Y., Ding, Z. F., You, H. C., Lou, H., Shao, C. R., 2015. Upper mantle anisotropy of the eastern Himalayan syntaxis and surrounding regions from shear wave splitting analysis. Science in China Series D: Earth Sciences 58(10), 1872-1882.

Chen, Y., Zhang, Z., Sun, C., Badal, J., 2013. Crustal anisotropy from Moho converted Ps wave splitting analysis and geodynamic implications beneath the eastern margin of Tibet and surrounding regions. Gondwana Research 24(3), 946-957.

ChinArray. 2006. China Seismic Array waveform data. China Earthquake Administration. doi:10.12001/ChinArray.Data.

ChinArray-Himalaya. 2011. China Seismic Array waveform data of Himalaya Project. Institute of Geophysics, China Earthquake Administration. doi:10.12001/ChinArray.Data. Himalaya.

Clearbout, J. F., 1976. Fundamentals of Geophysical Data Processing with 
Applications to Petroleum Prospecting. McGraw-Hill, New York, pp. 1-357.

Crampin, S., Lovell, J. H., 1991. A decade of shear-wave splitting in the Earth's crust: what does it mean? what use can we make of it? and what should we do next? Geophysics Journal International 107(3), 387-407.

Crampin, S., Chastin, S., 2003. A review of shear wave splitting in the crack-critical crust. Geophysics Journal International 155(1), 221-240.

Crampin, S., Peacock, S., 2008. A review of the current understanding of seismic shear-wave splitting in the Earth's crust and common fallacies in interpretation. Wave Motion 45(6), 675-722.

Fan, L. P., Wu, J. P., Fang, L. H., 2015. The characteristic of Rayleigh wave group velocities in the southeastern margin of the Tibetan Plateau and its tectonic implications (in Chinese). Chinese Journal of Geophysics 58, 1555-1567.

Flesch L. M., Holt, W. E., Silver, P. G., Stephenson, M., Wang, C., Chan, W. W., 2005. Constraining the extent of crust-mantle coupling in central Asia using GPS, geologic, and shear wave splitting data. Earth and Planetary Science Letters 238(1-2), 248-268. Hu, J., Su, Y., Zhu, X., Chen, Y., 2005. S-wave velocity and Poisson's ratio structure of crust in Yunnan and its implication. Science in China Series D: Earth Sciences 48(2), 210-218.

Kan, R., Hu, H., Zeng, R., Mooney, W. D., McEvilly, T. V., 1986. Crustal structure of Yunnan Province, People's Republic of China, from seismic refraction profiles. Science 234(4775), 433-437.

Katz, R. F., Spiegelman, M., Holtzman, B., 2006. The dynamics of melt and shear 
localization in partially molten aggregates. Nature 442(7103), 676-679.

Kohlstedt, D. L., Zimmerman, M. E., 2003. Rheology of partially molten mantle rocks. Annual Review of Earth and Planetary Sciences 24(24), 41-62.

Kreemer, C., Holt, W. E., Haines, A. J., 2003. An integrated global model of present-day plate motions and plate boundary deformation. Geophysics Journal International 154, 8-34.

Lev E., Long, M. D., Van der Hilst, R. D., 2006. Seismic anisotropy in Eastern Tibet from shear wave splitting reveals changes in lithospheric deformation. Earth and Planetary Science Letters 251, 293-304.

Liang S., Gan, W., Shen, C., Xiao, G., Liu, J., Chen, W., Xiao, D., Zhou, D., 2013. 3D velocity field of present-day crustal motion of the Tibetan Plateau derived from GPS measurements. Journal of Geophysical Research 118(10), 5722-5732.

Liu, H., Niu, F., 2012. Estimating crustal seismic anisotropy with a joint analysis of radial and transverse receiver function data. Geophysics Journal International 188(1), $144-164$.

McNamara, D. E., Owens, T. J., 1993. Azimuthal shear wave velocity anisotropy in the Basin and Range province using Moho Ps converted phases. Journal of Geophysical Research 98(B7), 12003-12017.

Meltzer, A. S., Bürgmann, R., van der Hilstet, R. D., King, R., Chen, Z., Koons, P. O., Lev, E., Liu, Y. P., Zeitler, P. K., Zhang, X., Zhang, J., Zurek, B., 2007. Geodynamics of the southeastern Tibetan Plateau from seismic anisotropy and geodesy. Geology 35(6), 563-566. 
Molnar, P., Tapponnier, P., 1975. Cenozoic tectonics of Asia: effects of a continental collision. Science 189(4201), 419-426.

Rabbel, W., Mooney, W. D., 1996. Seismic anisotropy of the crystalline crust: what does it tell us? Terra Nova 8(1), 16-21.

Replumaz, A., Tapponnier, P., 2003. Reconstruction of the deformed collision zone between India and Asia by backward motion of lithospheric blocks. Journal of Geophysical Research 108(B6), 2285, doi:10.1029/2001JB000661.

Rowley, D. B., 1996. Age of initiation of collision between India and Asia: a review of stratigraphic data. Earth and Planetary Science Letters 145(1), 1-13.

Shen, F., Royden, L. H., Burchfiel, B. C., 2001. Large - scale crustal deformation of the Tibetan Plateau. Journal of Geophysical Research 106(B4), 6793-6816.

Shi, Y., Gao, Y., Su, Y., Wang, Q., 2012. Shear-wave splitting beneath Yunnan area of Southwest China. Earthquake Science 25(1), 25-34.

Silver, P. G., 1996. Seismic anisotropy beneath the continents: probing the depths of geology. Annual Review of Earth and Planetary Sciences 24, 385-432.

Sun, Y., Niu, F., Liu, H., Chen, Y., Liu, J., 2012. Crustal structure and deformation of the SE Tibetan plateau revealed by receiver function data. Earth and Planetary Science Letters 349, 186-197.

Tatham, D., Lloyd, G., Butler, R., Casey, M., 2008. Amphibole and lower crustal seismic properties, Earth and Planetary Science Letters 267(1-2), 118-128.

Wang, C. Y., Chan, W. W., Mooney, W. D., 2003. Three-dimensional velocity structure of crust and upper mantle in southwestern China and its tectonic 
implications. Journal of Geophysical Research Solid Earth 108(B9), ESE 13-11.

Wang, C., Flesch, L. M., Silver, P. G., Chang, L., Chan, W. W., 2008. Evidence for mechanically coupled lithosphere in central asia and resulting implications. Geology 36(5), 363-366.

Wang, W., Wu, J., Fang, L., Lai, G., Yang, T., Cai, Y., 2014. S wave velocity structure in southwest China from surface wave tomography and receiver functions. Journal of Geophysical Research 119(2), 1061-1078.

Weiss, T., Siegesmund, S., Rabbel, W., Bohlen, T., Pohl, M., 1999. Seismic velocities and anisotropy of the lower continental crust: a review. Seismic Exploration of the Deep Continental Crust 156(1-2), 97-122.

Wu, J., Ming, Y., Wang, C., 2001. The S wave velocity structure beneath digital seismic stations of Yunnan province inferred from teleseismic receiver function modeling (in Chinese). Chinese Journal of Geophysics 44, 237-243.

Wu, J., Yang, T., Wang, W., Ming, Y., Zhang, T., 2013. Three dimensional P-wave velocity structure around Xiaojiang fault system and its tectonic implications (in Chinese). Chinese Journal of Geophysics 56(7), 2257-2267.

Wu, Q., Tian, X., Zhang, N., Li, W., Zeng, R., 2003. Receiver function estimated by maximum entropy deconvolution. Earthquake Science 16(4), 404-412.

Xu, Q., Wang, J. A., Wang, J. C., Zhang, W. R., 1992. Terrestrial heat flow and its tectonic significance in Yunnan, China (in Chinese). Geotectonica Et Metallogenia 16(3), 285-299.

Yang, Y., Zhu, L., Su, Y., Chen, H., Wang, Q., Zhang, P., 2015. Crustal anisotropy 
estimated by splitting of Ps-converted waves on seismogram and an application to SE Tibetan plateau. Journal of Asian Earth Sciences 106, 216-228.

Zhang, Z., Bai, Z., Wang, C., Teng, J., Lü, Q., Li, J., Liu, Y., Liu, Z., 2005a. The crustal structure under Sanjiang and its dynamic implications: Revealed by seismic reflection/refraction profile between Zhefang and Binchuan, Yunnan. Science in China Series D: Earth Sciences 48(9), 1329-1336.

Zhang, Z., Bai, Z., Wang, C., Teng, J., Lü, Q., Li, J., Sun, S., Wang, X., 2005b. Crustal structure of Gondwana-and Yangtze-typed blocks: an example by wide-angle seismic profile from Menglian to Malong in western Yunnan. Science in China Series D: Earth Sciences 48(11), 1828-1836.

Zhang, Z., Zhao, B., Zhang, X., Liu, C., 2006. Crustal structure beneath the wide angle seismic profile between Simao and Zhongdian in Yunnan (in Chinese). Chinese Journal of Geophysics 49(5), 1377-1384.

Zhu, L., Kanamori, H., 2000. Moho depth variation in southern California from teleseismic receiver functions. Journal of Geophysical Research 105(B2), 2969-2980. Zhu, S., Cai, Y., Shi, Y., 2005. Computation of the present-day strain rate field of the Qinghai-Tibetan plateau and its geodynamic implications (in Chinese). Chinese Journal of $\quad$ Geophysics $\quad 40(5), \quad 1053-1061$. 


\section{Figure Captions}

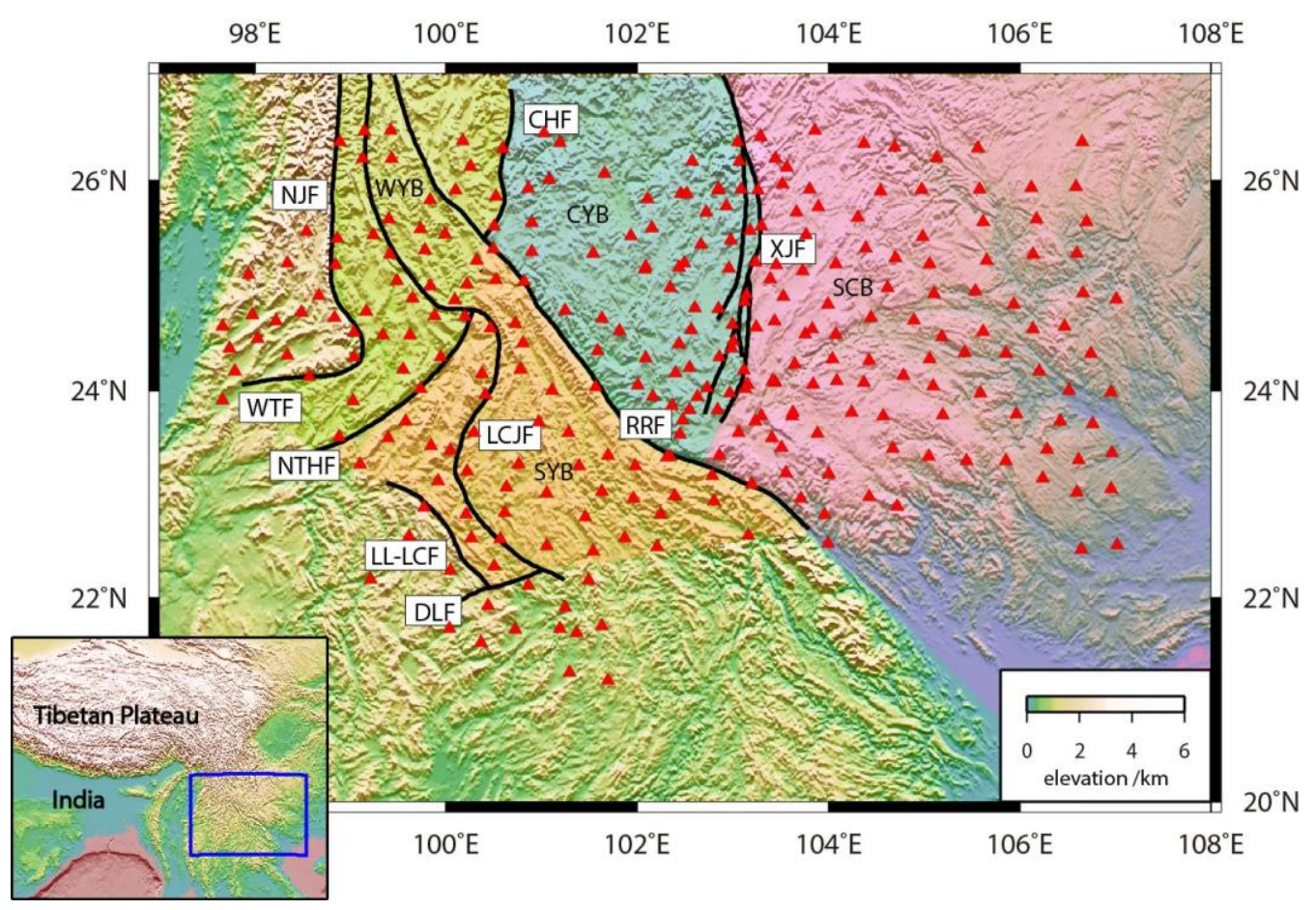

Fig. 1. Distributions of stations and faults in the study area.

Red triangles indicate seismic stations of ChinArray. Black lines indicate major faults.

The blocks are covered with different colors on the topographic map. NJF: Nujiang

Fault; CHF: Chenghai Fault; XJF: Xiaojiang Fault; WTF: Wanting Fault; NTHF:

Nantinghe Fault; LCJF: Lancangjiang Fault; RRF: Red River Fault; LL-LCF:

Longling-Lancang Fault; DLF: Daluo Fault; WYB: Western Yunnan sub-block; CYB:

Central Yunnan sub-block; SYB: Southern Yunnan sub-block; SCB: South China

block. The lower left inset shows the study region in Asia. Color coding is related

to topographic height. 


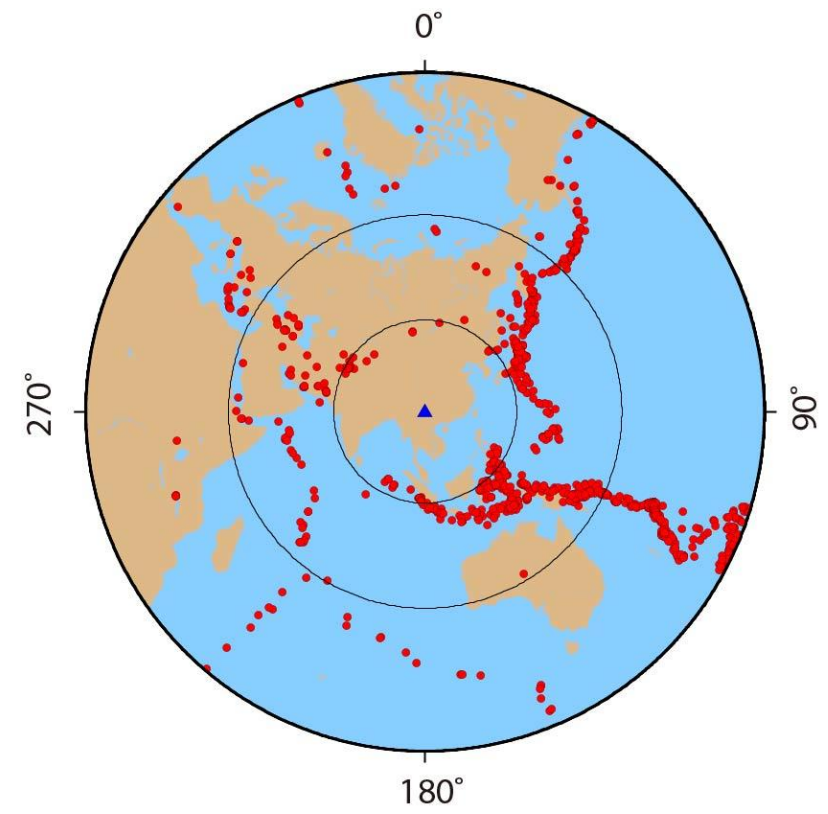

Fig. 2. Azimuthal distribution of the teleseismic events used in this study.

Red circles represent the teleseismic events. Blue triangle indicates the center of the seismic stations.
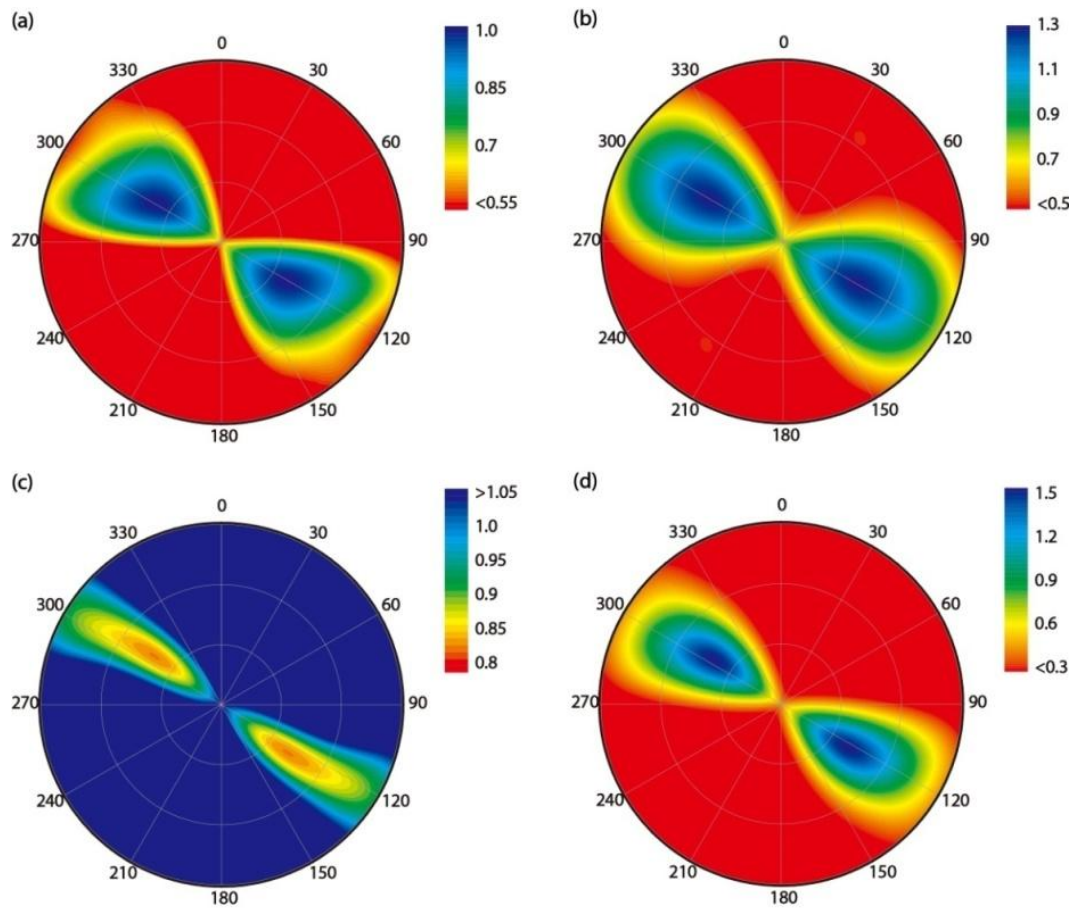

Fig. 3. Estimate of anisotropy at station 53133.

(a) - (d) correspond to the four objective functions for estimating the anisotropy, 
which are (1) maximizing the radial energy with a $\cos 2 \theta$ correction, (2) maximizing the radial correlation coefficient, (3) minimizing the transverse energy and (4) joint solution, respectively. Color varying from red to blue represents the values of the objective functions. The objective functions are calculated with two variables, $\varphi$ and $\delta$ t, where the range of $\varphi$ and $\delta \operatorname{tare} 0 \sim 360^{\circ}$ and $0 \sim 1.5 \mathrm{~s}$ with the step size of $1^{\circ}$ and $0.02 \mathrm{~s}$, respectively.

(a)

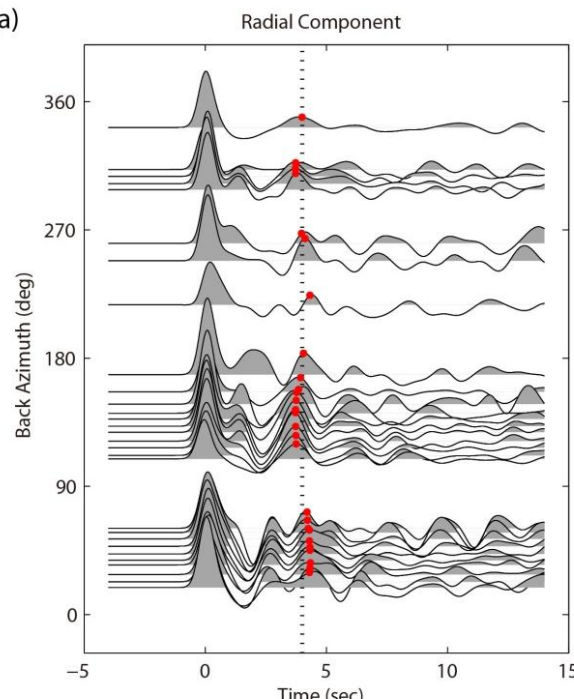

(c)

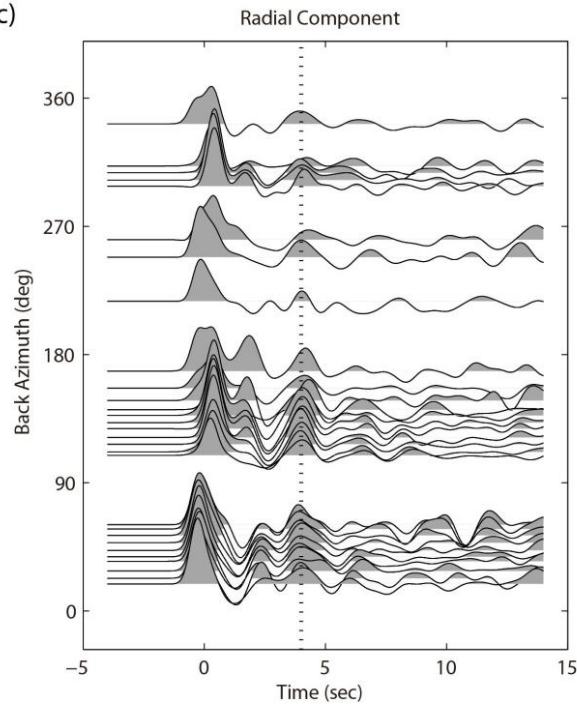

(b)

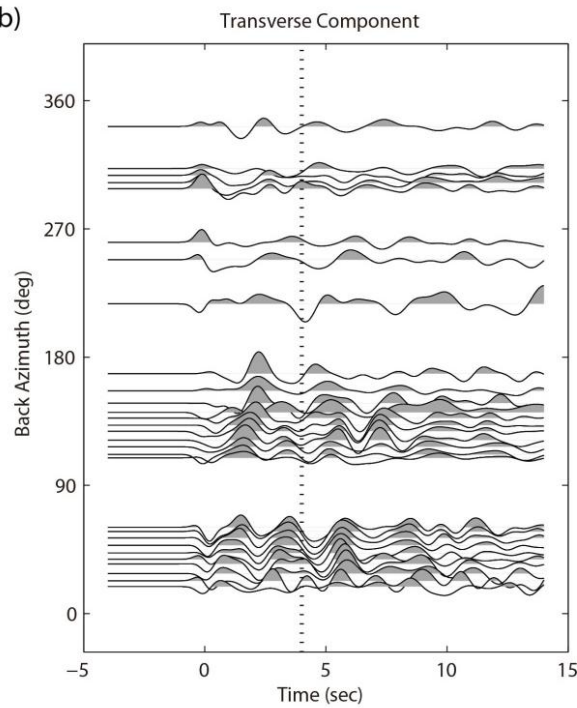

(d)

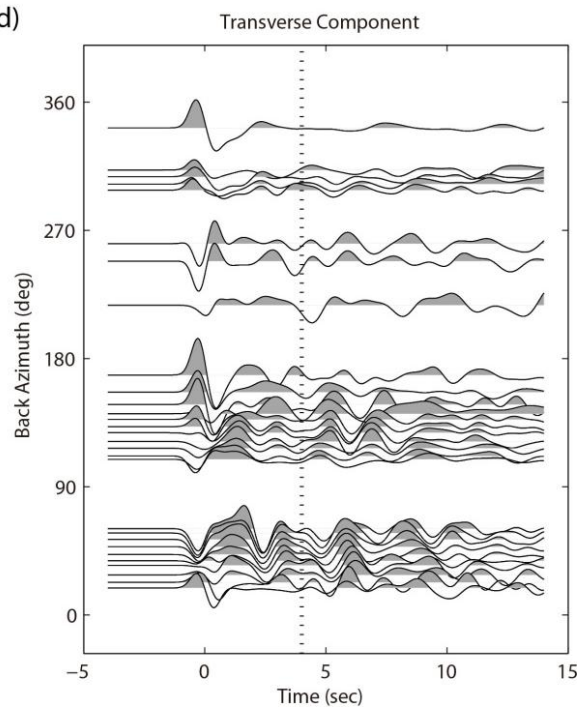

Fig. 4. The receiver functions of station 53133 before and after removing the crustal anisotropy. 
(a) and (b) show the original radial and transverse receiver functions. The red dots represent the peak energy of the Pms phase. After anisotropic correction, the corrected radial and transverse receiver functions are shown in (c) and (d). The dashed gray lines indicate the average arrival time of Pms phase.

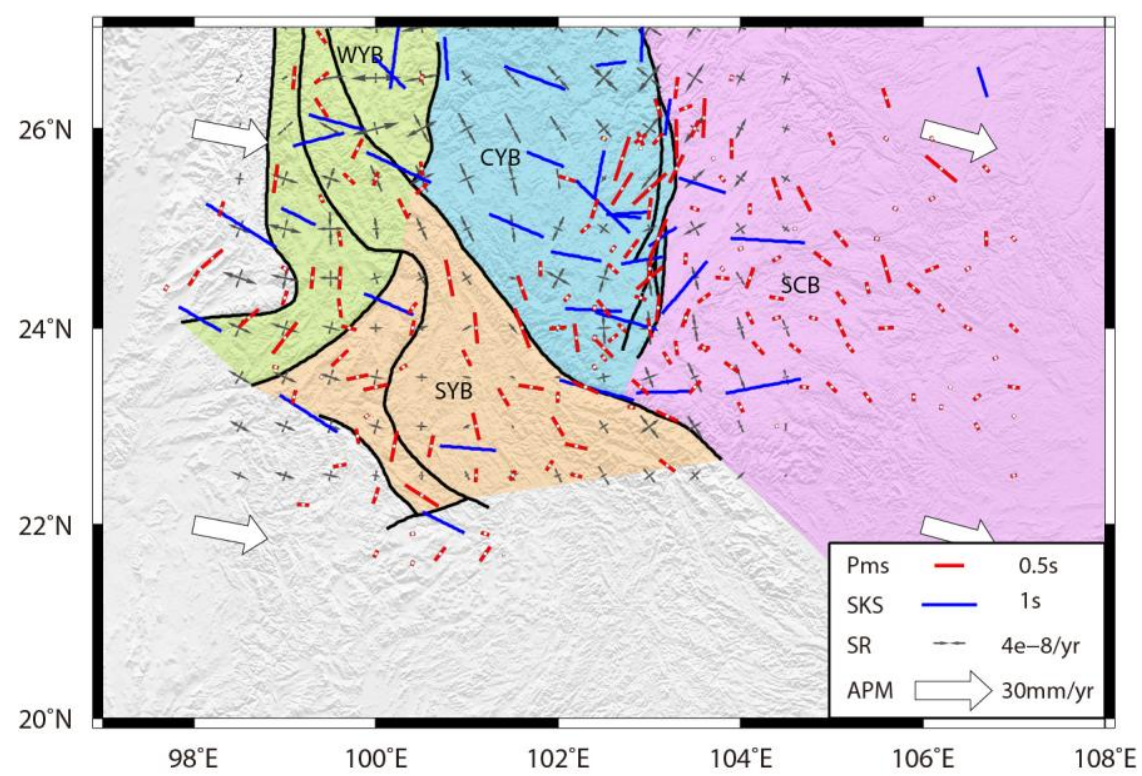

Fig. 5. The crustal anisotropy from Pms splitting estimated in this study, the results from SKS splitting (Wang et al., 2008), strain rate field (SR) and the Absolute Plate Motions (Kreemer et al. 2003).

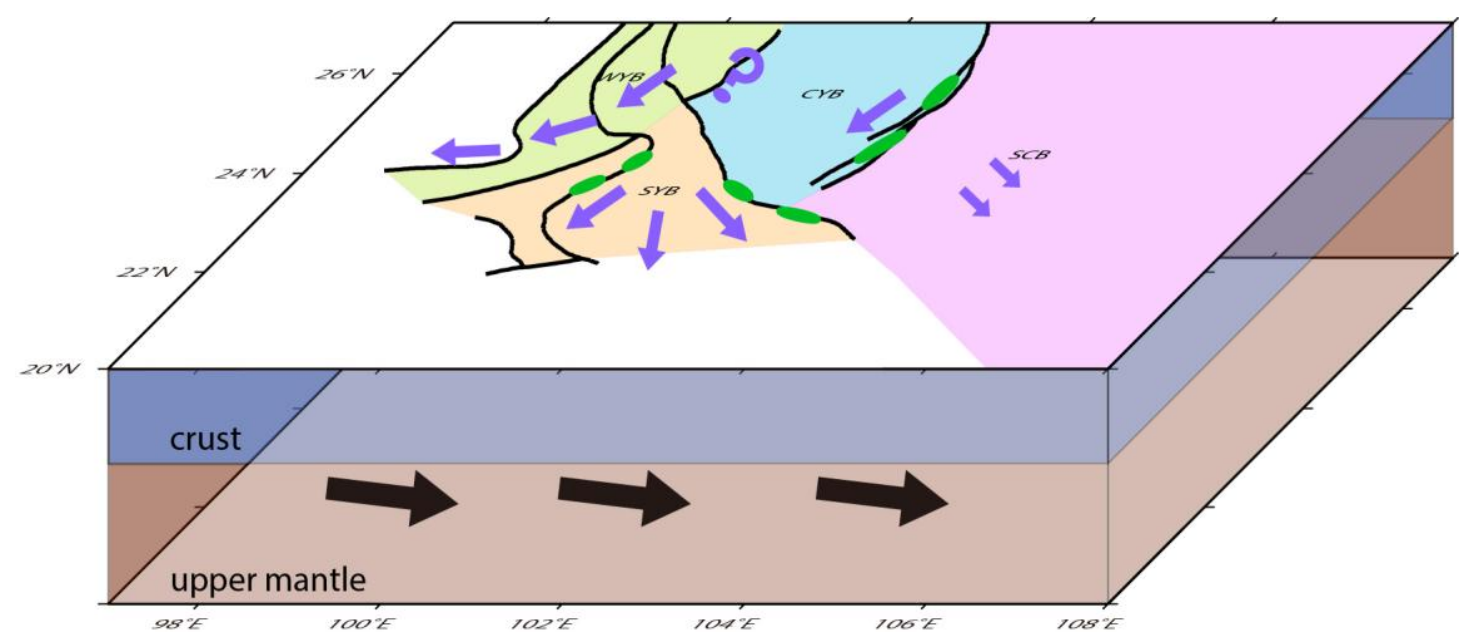


Fig. 6. Cartoon of the deformation in the SE margin of the Tibetan Plateau.

The green ellipses represent the crustal deformation features near the faults. The purple and black arrows show the deformation in the crust revealed in this work and upper mantle derived by SKS splitting (Wang et al., 2008), and the length of arrow represents roughly the deformation intensity. 